ISSN 0103-9954

\title{
CARACTERIZAÇÃO FLORÍSTICA E FITOSSOCIOLÓGICA DE UM TRECHO SAZONALMENTE INUNDÁVEL DE FLORESTA ALUVIAL, EM ARAUCÁRIA, PR
}

\author{
FLORISTIC AND PHYTOSOCIOLOGIC CHARACTERIZATION OF A FLOODPLAIN FOREST, AT \\ ARAUCARIA, PR
}

\author{
Murilo Lacerda Barddal ${ }^{1} \quad$ Carlos Vellozo Roderjan ${ }^{2}$ Franklin Galvão ${ }^{3}$ Gustavo Ribas Curcio ${ }^{4}$

\section{RESUMO}

Foi estudado o componente arbustivo-arbóreo de uma floresta sazonalmente inundável, localizada na planície aluvial do rio Barigüi, em Araucária-PR. Limitou-se a área investigada aos locais de mesmo tipo de solo (Gleissolos) e mediu-se a profundidade do lençol freático no centro de 20 parcelas de $100 \mathrm{~m}^{2}$, correlacionando tais fatores físicos com os parâmetros fitossociológicos obtidos. Avaliaram-se todos os indivíduos com perímetro à altura do peito (PAP) igual ou supeior a $15 \mathrm{~cm}$, encontrando-se 29 espécies, sendo Sebastiania commersoniana (Baillon) L.B. Smith e R.J. Downs (branquilho) a mais importante delas, seguida por Allophylus edulis (A.St.-Hil., Cambess. e A. -Juss.) Radlk. (vacum). Em resposta à severidade do ambiente, constatou-se o pequeno porte dos indivíduos que formam a comunidade, além da grande incidência de exemplares com vários troncos e a destacada importância das árvores mortas. Da interação com o meio físico, notou-se que os locais menos saturados hidricamente possibilitaram maior crescimento diamétrico da comunidade e que a maior parte das espécies de baixos valores fitossociológicos estabeleceram-se apenas nas micro-elevações do terreno, de melhor aeração.

Palavras-chave: floresta inundável; composição florística e estrutura.

\section{ABSTRACT}

The shrub-arboreal component of a floodplain forest, located in the alluvial plain of the Barigui River in Araucaria-PR was studied. The researched area was limited to places of same soil type (Glei soil) and the level of the water table was measured in a central point of the 20 plots of $100 \mathrm{~m}^{2}$, correlating this physiographic feature with the obtained phytosociologic parameters. The individuals with minimal perimeter of breast height $(\mathrm{PBH})$ of $15 \mathrm{~cm}$ were valued, resulting in 29 species found. The most important was Sebastiania commersoniana (Baillon) L.B. Smith and R.J. Downs (branquilho), followed by Allophylus edulis (A.St.-Hil., Cambess. e A.-Juss.) Radlk. (vacum). The small sise of the individuals, the large number of individuals with multiple boles and the expressive importance of dead trees were atributed to enviromental stress. Less flooded places provided better diametric development and only at the micro-topographic elevations most species of lower phytosociologic values were established.

Key words: floodplain forest; floristic composition and structure.

\section{INTRODUÇÃO}

Parte importante dos rios do Primeiro Planalto paranaense é drenada pela bacia hidrográfica do rio Iguaçu, desenvolvendo-se às suas margens e na de seus afluentes as principais cidades dessa região, inclusive Curitiba, a capital do estado. Em função do crescimento urbano, essas áreas sofreram intensa modificação, quando alguns cursos de água foram simplesmente retificados ou mesmo canalizados. Com esse modelo de desenvolvimento regional, grande parte das várzeas e das florestas da planície inundável do rio Barigüi, afluente do Iguaçu, deram lugar a áreas urbanas e industriais que, não raras vezes, são "invadidas" pelas águas do rio, causando inúmeros problemas sócio-econômicos.

1. Engenheiro Florestal, MSc., Doutorando em Engenharia Florestal pela Universidade Federal do Paraná, CEP 80210-170, Curitiba (PR). mbarddal@floresta.ufpr.br

2. Engenheiro Florestal, Dr., Professor Adjunto do Departamento de Ciências Florestais, Universidade Federal do Paraná, CEP 80210-170, Curitiba (PR). roderjan@floresta.ufpr.br

3. Engenheiro Florestal, Dr., Professor Adjunto do Departamento de Ciências Florestais, Universidade Federal do Paraná, CEP 80210-170, Curitiba (PR). fgalvao@floresta.ufpr.br

4. Engenheiro Agrônomo, MSc., Doutorando em Engenharia Florestal pela Universidade Federal do Paraná, Pesquisador da Embrapa Florestas, CEP 83405-970, Colombo (PR). curcio@enpf.embrapa.br

Recebido para publicação em 18/11/2002 e aceito em 18/11/2003. 
Nos últimos anos, todavia, a necessidade de preservação e recuperação dessas áreas se faz premente. Contudo, a enorme carência de informações a respeito das interações ecológicas que as envolvem dificultam ações seguras nesse sentido.

Alguns estudos que abordaram esse bioma (Galvão et al., 1989; Ziller, 1993; Bufren, 1997; Oliveira, 2001 e Souza, 2001), mesmo tendo importância inconteste, não trataram do tema com maior profundidade, por isso a importância de outros trabalhos que os complementem.

Assim, propôs-se estudar a composição florística e a estrutura fitossociológica da comunidade arbustivo-arbórea, popularmente conhecida como branquilhal, em área de influência do rio Barigüi, na Região Metropolitana de Curitiba. E como a vegetação dessas áreas possui estreita relação com o componente hidro-geomorfológico, principal responsável pela sua diversidade (Gurnel, 1997), procurou-se também correlacionar os parâmetros fitossociológicos com os fatores pedológicos e com a variação do lençol freático, subordinados pelas condições de relevo local.

\section{MATERIAL E MÉTODO}

\section{Área de estudos}

Localizada no município de Araucária, porção centro-sul do Primeiro Planalto paranaense, a área em questão situa-se entre as coordenadas aproximadas de $25^{\circ} 35^{\prime} 12^{\prime \prime} \mathrm{S}$ e $49^{\circ} 20^{\prime} 45^{\prime \prime} \mathrm{W}$ (Figura 1). O acesso principal, a partir de Curitiba, é feito pela BR 476, poucos quilômetros antes do centro urbano de Araucária. Está estabelecida em uma planície inundável, onde predominam solos naturalmente hidromórficos, sendo comuns os Gleissolos, associados, de forma geral, a Organossolos e Neossolos Flúvicos, entre outras variações (Resck e Silva, 1998). Os Gleissolos são os mais importantes para este estudo, sendo de origem alúvio-coluvionar, formados por sedimentos de fina granulometria. Possuem, normalmente, grande quantidade de argila e sua consistência é muito dura quando secos e muito plástica e pegajosa quando molhados, sendo pouco porosos e de baixa condutividade hídrica. Assim, estão permanente ou periodicamente saturados por água (mal ou muito mal drenados) em condições naturais (EMBRAPA, 1999; Rauen et al., 1990).
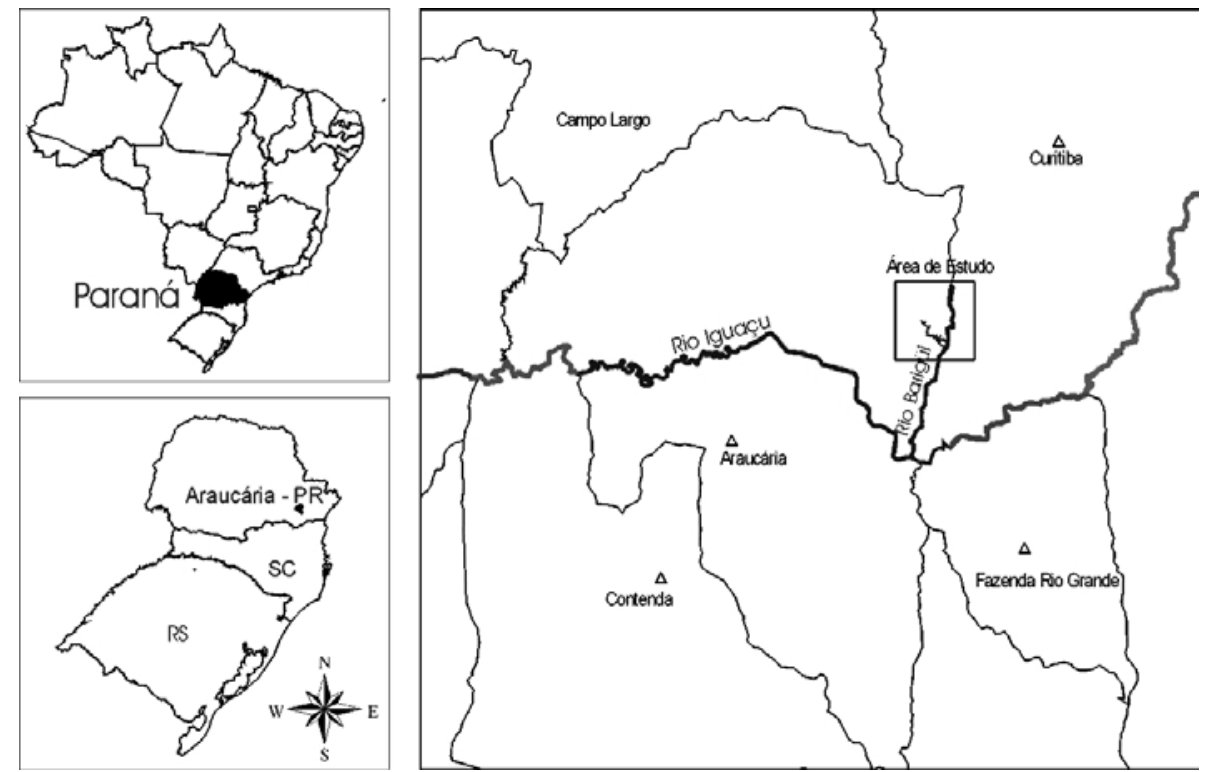

FIGURA 1: Localização da área de estudos.

FIGURE 1: Localization of the studied area.

O clima é o Cfb (Koeppen), com chuvas bem distribuídas anualmente (1300-1500 mm/ano) e inverno rigoroso. A temperatura média anual do mês mais quente é inferior a $22{ }^{\circ} \mathrm{C}$ e a do mês mais frio inferior a $18^{\circ} \mathrm{C}$.

O principal corpo d'água no local é o rio Barigüi, o qual, neste trecho, teve seu curso alterado já em meados da década de 1960, por ação do Departamento Nacional de Obras de Saneamento, visando propiciar 
maior vazão e minimizar o efeito das enchentes (DNOS, 1979). Ainda, cortando a área de estudo em direção ao Barigüi, encontra-se o arroio Saldanha, pequeno tributário com pouco mais de $2,2 \mathrm{~km}$ de extensão em linha reta (desconsiderando os meandros) (Figura 2).

Quanto à vegetação arbórea nas proximidades do rio Barigüi, enquadrada pelo IBGE (1992) como Floresta Ombrófila Mista Aluvial, encontra-se em bom estado de conservação, preservando, em grande parte, as suas características originais. Contudo, é possível que, mesmo sem aparente interferência humana, tenha tido sua estrutura alterada após a modificação do curso e do leito do rio Barigüi e, conseqüentemente, das características hídricas locais. O dique marginal ao rio sofreu alteração de sua configuração natural, tendo seu porte aumentado por ocasião destas atividades, razão pela qual, neste trabalho, ele foi evitado.

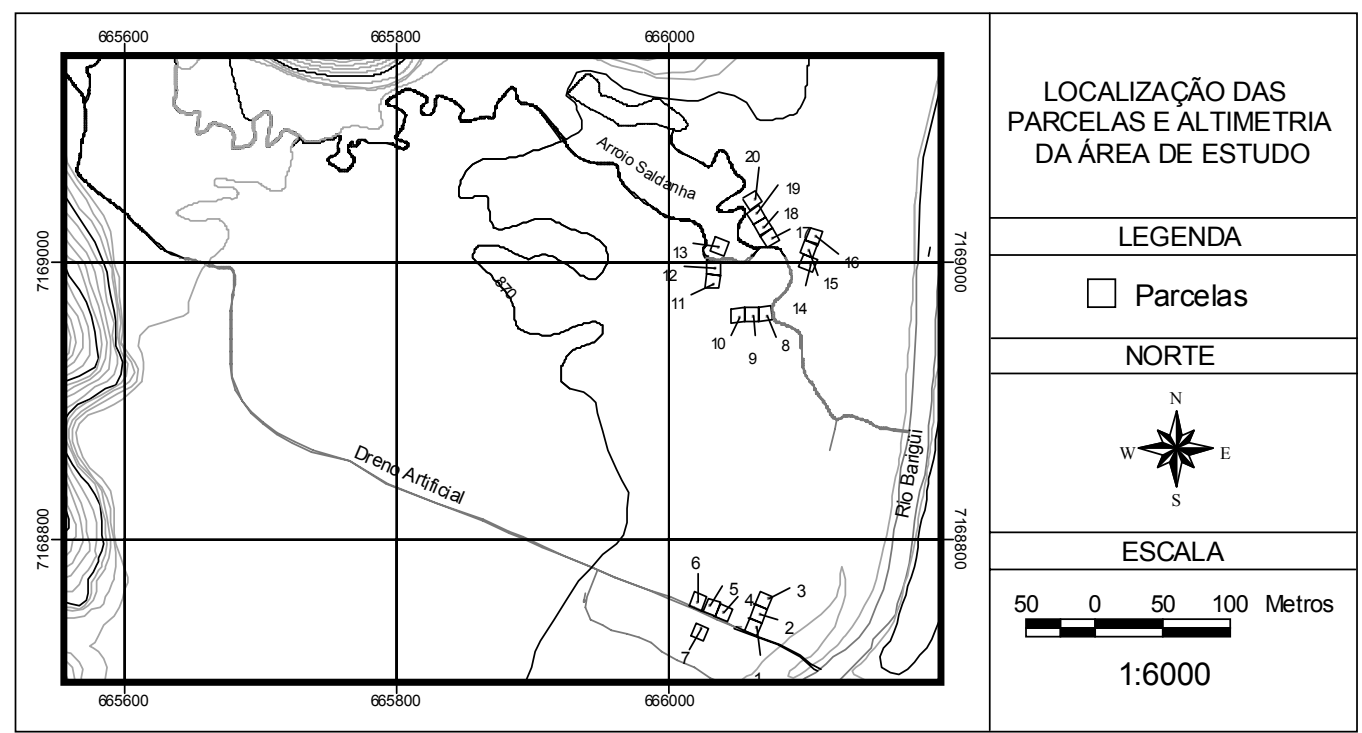

FIGURA 2: Mapa plani-altimétrico da área de estudo e disposição das parcelas em campo. FIGURE 2: Topographyc map of the studied area showing the plots distribution.

\section{Procedimento metodológico}

\section{Avaliação fitossociológica}

Como as planícies inundáveis são áreas consideradas muito variáveis topográfica e pedologicamente, mesmo a pequenas distâncias, devido à dinâmica de deposição dos sedimentos que as conformam, ocasionando diferenças de distribuição e desenvolvimento de espécies e comunidades vegetais (VivianSmith, 1997; Almquist, 1999; Ab `Saber, 2000), procurou-se homogeneizar, da melhor maneira possível, a comunidade florestal estudada. Para tanto, as amostras foram alocadas em posições específicas, previamente observadas, sobre mesma classe pedológica, neste caso, ordem dos Gleissolos.

O estudo fitossociológico seguiu a metodologia proposta por Mueller-Dombois e Ellemberg (1974), e, para tanto, foram instaladas em campo 20 (vinte) parcelas de $10 \times 10 \mathrm{~m}\left(100 \mathrm{~m}^{2}\right)$, onde foram avaliados todos os indivíduos arbóreos e arbustivos com perímetro à altura do peito (PAP) igual ou superior a $15 \mathrm{~cm}$ (4,8 cm de diâmetro).

Em fichas específicas de campo, anotaram-se a espécie botânica, a altura total estimada e do ponto de inversão morfológica (ramificação do fuste) e a posição sociológica, verificando a qual estrato pertence cada indivíduo (Galvão, 1994). Para o caso de exemplares com vários troncos, foram considerados aqueles em que ao menos uma das ramificações tivesse mais de $15 \mathrm{~cm}$ de PAP, medindo-se, então, todo o conjunto. As árvores mortas em pé, por dividirem o espaço com as demais, foram consideradas e agrupadas na classe "mortas".

Os dados obtidos em campo foram ordenados e processados no programa FITOPAC I (Shepherd, 
1988), resultando nos descritores fitossociológicos de densidade, freqüência, dominância e valor de importância (Daubenmire, 1968; Mueller-Dombois e Ellenberg, 1974), além dos índices de diversidade de Shannon (H') e Simpson (D) na base logarítmica natural e a eqüabilidade correspondente (E) (Magurran, 1989).

O material botânico de cada espécie foi coletado, preparado de acordo com IBGE (1992), depositado e registrado (quando fértil) no herbário do Curso de Engenharia Florestal da Universidade Federal do Paraná (EFC). Sua determinação foi feita por meio de comparação com exsicatas do EFC e mediante consulta aos especialistas Sandro Menezes Silva, do Departamento de Botânica da UFPR, e Marcos Sobral, do Departamento de Farmácia da Universidade Federal do Rio Grande do Sul.

\section{Caracterização pedológica}

Para a caracterização pedológica, foram efetuadas tradagem e coleta dos horizontes A e C do solo no centro de todas as parcelas (20 pontos de amostra), ao mesmo tempo em que era feita sua descrição morfológica. As amostras foram enviadas ao laboratório de Solos e Nutrição Florestal da Embrapa Florestas, onde, seguindo as normas da própria EMBRAPA (1979), foram feitas as análises químicas e granulométricas. A partir desses resultados, foi realizada a classificação dos solos segundo os critérios do Sistema Brasileiro de Classificação dos Solos (EMBRAPA, 1999).

\section{Avaliação do lençol freático}

Próximo ao centro de cada parcela, foi instalado um piezômetro com $1,20 \mathrm{~m}$ de profundidade a fim de avaliar a variação do nível do lençol freático. A verificação da profundidade da água subterrânea era feita diretamente através de uma régua graduada, medindo-se desde a superfície do solo até a lâmina d' água. Esse procedimento foi realizado no período de agosto a novembro de 2001, em intervalos de aproximadamente sete dias.

\section{Análises estatísticas}

Para as análises estatísticas, utilizou-se o programa Statistica for Windows Release 5.1, sendo que as parcelas foram agrupadas segundo seu distanciamento geográfico. As variáveis fitossociológicas envolvidas nestes cálculos foram altura média (h), diâmetro médio (d), número de espécies ( $\mathrm{n}^{\circ} \mathrm{spp}$ ), densidade absoluta (DA) e dominância absoluta (DoA).

\section{RESULTADOS E DISCUSSÃO}

\section{Flutuação do lençol freático}

Embora tenham sido efetuados apenas quatro meses de medições, pôde-se estimar um valor médio da flutuação do lençol freático para as 20 parcelas, conforme pode ser visto na Figura 3. Os meses avaliados correspondem a um período intermediário de chuvas para a Região Metropolitana de Curitiba, pois, de acordo com as análises pluviométricas de Danni-Oliveira (1997), essas médias estariam mais baixas, se medidas entre abril e agosto, e mais altas de dezembro a março.

Um primeiro grupo de parcelas (1-7), por estar mais próximo do curso do rio, o qual proporciona um rebaixamento do lençol freático, e por estar ligeiramente mais elevado que os demais grupos, por influência do dique marginal, teve as maiores profundidades. Nota-se, contudo, que esse conjunto é o que possui maiores variações internas, tendo maior diferença entre as parcelas $3(86,4 \mathrm{~cm})$ e $6(38 \mathrm{~cm})$. Tal diferença não ocorre por acaso, já que por terem uma distribuição transversal na planície, as parcelas 4,5 e 6 ficaram mais afastadas do rio Barigüi, em locais pouco mais baixos, nas proximidades da bacia de inundação. 


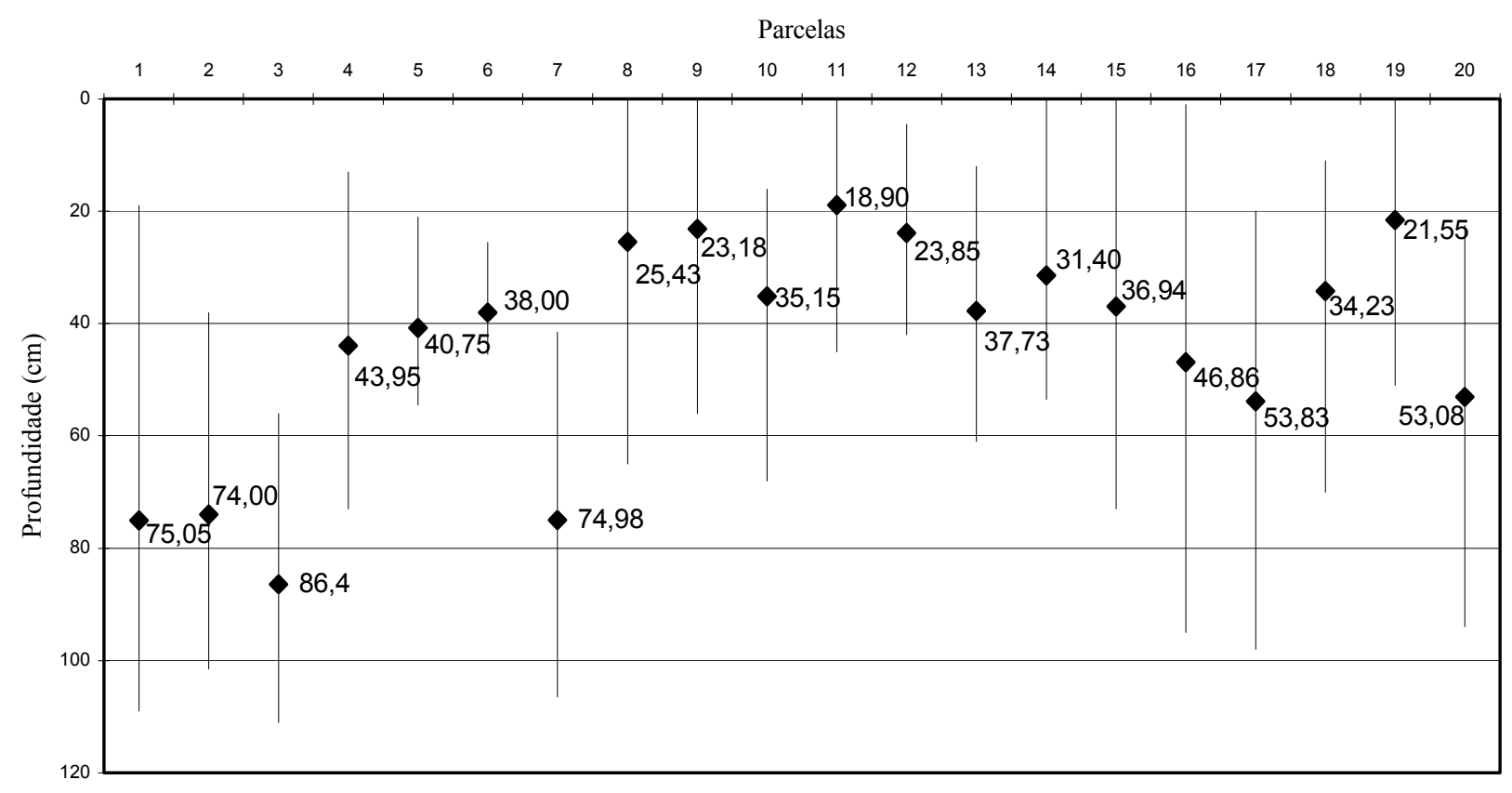

FIGURA 3: Amplitude e valor médio da profundidade do lençol freático no interior das parcelas, calculada através das observações semanais realizadas durante 4 meses.

FIGURE 3: Amplitude and average value of the water table depth, calculated by weekly observations, during 4 months.

Um segundo grupo (8-13) está mais próximo da bacia de inundação e, em função disso, o lençol freático permanece a pequena profundidade. Não ocorreu variação importante entre as parcelas, sendo a maior entre $11(18,90 \mathrm{~cm})$ e $13(37,73 \mathrm{~cm})$.

Com relação aos anteriores, um terceiro grupo de parcelas (14-20) continua afastado do rio Barigüi, enquanto a água subterrânea se mantém em profundidades intermediárias, variando de acordo com as diferenças microtopográficas, entre 21,55 $\mathrm{cm}$ (parcela 19) e 53,83 $\mathrm{cm}$ (parcela 17).

\section{Solos}

A área de estudo abrangeu unicamente os solos hidromórficos minerais da ordem dos Gleissolos (Tabela 1), sendo que 11 parcelas estavam inseridas na categoria dos Háplicos, de cor mais clara (normalmente 10YR 4/2), e 9 delas na dos Melânicos, mais escurecidos (10 YR 3/2). Todos apresentaram alto valor de T, ou seja, alta atividade (capacidade de troca de cátions) da fração argila, representada por Ta.

O caráter Distrófico (baixa saturação por bases) foi encontrado apenas no grupo 1 (exceto na parcela 5), sendo todo o restante Eutrófico (alta saturação por bases), inclusive com algumas parcelas (11 e 13) com horizonte A chernozêmico, cuja saturação por bases exigida deve ser superior a $65 \%$.

Foram identificadas texturas médias (parcelas 1, 10 e 16), argilosas (2-9, 11,12,17,18 e 20) e muito argilosas (13-15 e 19), demonstrando a volubilidade do ambiente pedológico nessas áreas. A variabilidade na distribuição das frações granulométricas ao longo e entre os pedons caracteriza a dinâmica de distribuição dos sedimentos na planície, confirmando Oliveira et al. (1992).

Em média, a quantidade de argila nos ambientes mais interiorizados (grupos 2 e 3 ) é maior do que aquele localizado próximo do rio (bloco 1), sendo esse último mais siltoso, distribuição em conformidade com as descrições de Christofoletti (1981) e Suguio e Bigarella (1990). Em compensação, a porcentagem de areia entre os grupos 1 e 3 é muito parecida e bem maior do que a do grupo intermediário. Para o primeiro, já era de se esperar, em função de sua proximidade junto ao dique marginal, no qual fica retida a areia provinda do Barigüi. Contudo, o grupo 3 também foi mais arenoso, provavelmente, por influência do cone de dejeção do arroio Saldanha. 
TABELA 1: Classificação dos solos encontrados ao longo das parcelas demarcadas no levantamento da floresta aluvial do rio Barigüi.

TABLE 1: Soil classification alongside of the floodplain forest of the Barigui River.

\begin{tabular}{c|c}
\hline Parcelas & \multicolumn{1}{c}{ Classificação } \\
\hline 1 & GLEISSOLO HÁPLICO Ta Distrófico típico, A moderado, textura média, relevo plano \\
\hline 2 & GLEISSOLO HÁPLICO Ta Distrófico típico, A moderado, textura argilosa, relevo plano \\
\hline 3 & GLEISSOLO HÁPLICO Ta Distrófico típico, A moderado, textura argilosa, relevo plano \\
\hline 4 & GLEISSOLO HÁPLICO Ta Distrófico típico, A moderado, textura argilosa, relevo plano \\
\hline 5 & GLEISSOLO MELÂNICO Eutrófico típico, A proeminente, textura argilosa, relevo plano \\
\hline 6 & GLEISSOLO MELÂNICO Distrófico típico, A proeminente, textura argilosa, relevo plano \\
\hline 7 & GLEISSOLO HÁPLICO Ta Distrófico típico, A moderado, textura argilosa, relevo plano \\
\hline 8 & GLEISSOLO MELÂNICO Eutrófico típico, A prominente, textura argilosa, relevo plano \\
\hline 10 & GLEISSOLO MELÂNICO Eutrófico típico, A prominente, textura argilosa, relevo plano \\
\hline 11 & GLEISSOLO MELÂNICO Eutrófico típico, A prominente, textura média, relevo plano \\
\hline 12 & GLEISSOLO MELÂNICO Eutrófico típico, A chernozêmico, textura argilosa, relevo plano \\
\hline 13 & GLEISSOLO HÁPLICO Ta Eutrófico típico, A moderado, textura argilosa, relevo plano \\
\hline 14 & GLEISSOLO MELÂNICO Eutrófico típico, A chernozêmico, textura muito argilosa, relevo plano \\
\hline 15 & GLEISSOLO HÁPLICO Ta Eutrófico típico, A moderado, textura muito argilosa, relevo plano \\
\hline 16 & GLEISSOLO HÁPLICO Ta Eutrófico típico típico, A moderado, textura muito argilosa, relevo plano \\
\hline 17 & GLEISSOLO HÁPLICO Ta Eutrófico típico, A moderado, textura média, relevo plano \\
\hline 18 & GLEISSOLO HÁPLICO Ta Eutrófico típico, A moderado, textura argilosa, relevo plano \\
\hline 19 & GLEISSOLO MELÂNICO Eutrófico típico, A proeminente, textura muito argilosa, relevo plano \\
\hline 20 & GLEISSOLO MELÂNICO Eutrófico típico, A proeminente, textura argilosa, relevo plano \\
\hline
\end{tabular}

Os Gleissolos encontrados estão sob regime de hidromorfia imperfeitamente drenados a muito mal drenados, revelados pelos mosqueados freqüentes contidos nos horizontes $\mathrm{Cg}$ e pela profundidade do lençol freático. Observou-se uma associação quase perfeita entre os Gleissolos Melânicos e as áreas de maior saturação hídrica e dos Háplicos com as menos saturadas, percebendo-se a interdependência entre esses fatores.

Foram identificadas também variações dos teores de matéria orgânica (MO), as quais se justificam pelas alterações microtopográficas da superfície (rugosidade da superfície), pois, nas porções mais elevadas e também nas planas, ocorre uma lavagem da serapilheira que se acumula somente nos abaciados, alterando esses valores. Sobre isso, Vivian-Smith (1997) destacou que as diferenças de microrrelevo alterariam não só a acumulação da serapilheira, mas também a mudança do potencial de redução (redox) e de níveis de compactação do solo.

\section{Fitossociologia geral da área}

\section{Composição florística e estimativa dos parâmetros fitossociológicos}

Para os $2000 \mathrm{~m}^{2}$ estudados, foram encontradas 29 espécies botânicas, pertencentes a 27 gêneros e 16 famílias (Tabela 2) que, somadas às árvores mortas e em pé, resultaram em 537 indivíduos avaliados.

As famílias de maior expressão foram Euphorbiaceae e Myrtaceae. A primeira, contando com apenas duas espécies, atingiu o maior valor de importância (VI - 148,13), mantendo-se bem à frente da outra que obteve VI de 38,05, mas que, todavia, concentrou o maior número de espécies (9), 28,99\% do total. Em trabalhos realizados em florestas inundáveis no estado de São Paulo (Ivanauskas et al., 1997 e Toniato et al., 1998), mesmo que inseridos em outra unidade fitogeográfica (Floresta Estacional Semidecidual), estas famílias também ocuparam posição de destaque.

Logo depois, seguiram Anacardiaceae (VI - 24,67), Sapindaceae $(23,95)$, Rubiaceae $(8,39)$, Rhamnaceae $(7,26$, sendo uma de suas duas espécies, exótica) e Fabaceae $(7,09)$, enquanto as outras nove famílias ficaram com VI abaixo de 3,70. 
TABELA 2: Composição florística da floresta aluvial do rio Barigüi.

TABLE 2: Floristic composition of floodplain forest of the Barigui River.

\begin{tabular}{|c|c|c|c|c|}
\hline N. & Família & Espécie/Autor & Nome Popular & Hábito \\
\hline $\begin{array}{l}1 \\
2\end{array}$ & Anacardiaceae & $\begin{array}{l}\text { - Lithraea brasiliensis March. } \\
\text { - Schinus terebinthifolius Raddi }\end{array}$ & $\begin{array}{l}\text { bugreiro } \\
\text { aroeira }\end{array}$ & $\begin{array}{l}\mathrm{AR} \\
\mathrm{AR}\end{array}$ \\
\hline 3 & Arecaceae & - Syagrus romanzoffiana (Cham.) Glassman & jerivá & AR \\
\hline $\begin{array}{l}4 \\
5\end{array}$ & Euphorbiaceae & $\begin{array}{l}\text { - Sebastiania brasiliensis Spreng. } \\
\text { - Sebastiania commersoniana (Baillon) L.B. Smith e R.J. Downs }\end{array}$ & $\begin{array}{l}\text { leiteiro } \\
\text { branquilho }\end{array}$ & $\begin{array}{l}\mathrm{AB} / \mathrm{Ar} \\
\mathrm{AR}\end{array}$ \\
\hline $\begin{array}{l}6 \\
7\end{array}$ & Fabaceae & $\begin{array}{l}\text { - Dalbergia frutescens (Vell.) Britton } \\
\text { - Machaerium paraguariense Hassl. }\end{array}$ & $\begin{array}{l}\text { rabo-de-bugiu } \\
\text { sapuva }\end{array}$ & $\begin{array}{l}\mathrm{Ar} / \mathrm{AR} \\
\mathrm{AR}\end{array}$ \\
\hline $\begin{array}{l}8 \\
9 \\
\end{array}$ & Flacourtiaceae & $\begin{array}{l}\text { - Casearia decandra Jacq. } \\
\text { - Xylosma pseudosalzmannii Sleumer }\end{array}$ & $\begin{array}{l}\text { guaçatunga } \\
\text { sucará }\end{array}$ & $\begin{array}{l}\mathrm{AB} / \mathrm{Ar} \\
\mathrm{AB} / \mathrm{Ar}\end{array}$ \\
\hline 10 & Meliaceae & - Trichilia elegans A. - Juss. & catiguá & $\mathrm{Ar}$ \\
\hline 11 & Mimosaceae & - Inga marginata Willd. & ingá & $\mathrm{AR}$ \\
\hline 12 & & - Blepharocalyx salicifolius (Kunth) O. Berg & murta & AR \\
\hline 13 & & - Calyptranthes concinna DC. & guamirim-de-facho & $\mathrm{AB} / \mathrm{Ar}$ \\
\hline 14 & & - Campomanesia xanthocarpa O. Berg & guabiroba & AR \\
\hline 15 & & - Eugenia uniflora L. & pitanga & $\mathrm{AB} / \mathrm{Ar}$ \\
\hline 16 & Myrtaceae & - Eugenia uruguayensis Cambess. & batinga-vermelha & AR \\
\hline 17 & & - Myrceugenia glaucescens (Cambess.) D. Legrand et Kausel. & guamirim & $\mathrm{AR} / \mathrm{Ar}$ \\
\hline 18 & & - Myrcianthes gigantea (D. Legrand) D. Legrand & araçá-do-mato & AR \\
\hline 19 & & - Myrciaria tenella (DC.) O. Berg & cambuí & $\mathrm{AB} / \mathrm{Ar}$ \\
\hline 20 & & - Myrrhinium atropurpureum Schott & murtilho & $\mathrm{Ar}$ \\
\hline 21 & Oleaceae & - Ligustrum vulgare L. & alfeneiro* & $\mathrm{AR}$ \\
\hline $\begin{array}{l}22 \\
23\end{array}$ & Rhamnaceae & $\begin{array}{l}\text { - Hovenia dulcis Thunb. } \\
\text { - Scutia buxifolia } \text { Reissek }\end{array}$ & $\begin{array}{l}\text { uva-do-japão* } \\
\text { coronilha }\end{array}$ & $\begin{array}{c}\text { AR } \\
\text { Ar/AR }\end{array}$ \\
\hline 24 & Rosaceae & - Prunus cf. sellowii Koehne & pessegueiro-bravo & AR \\
\hline 25 & Rubiaceae & - Guettarda uruguensis Cham. et Schltdl. & veludo & $\mathrm{AB}$ \\
\hline 26 & Sapindaceae & - Allophylus edulis (A.St.-Hil., Cambess. e A. -Juss.) Radlk. & vacum & AR \\
\hline 27 & Simaroubaceae & - Picramnia parvifolia Engl. & cedrinho & $\mathrm{Ar}$ \\
\hline 28 & Tiliaceae & - Luehea divaricata Mart. et Zucc. & açoita-cavalo & AR \\
\hline 29 & Verbenaceae & - Vitex megapotamica (Spreng.) Moldenke & tarumã & AR \\
\hline
\end{tabular}

Em que: $\mathrm{AR}=$ Arbóreo; $\mathrm{Ar}=$ Arbóreo (arvoreta); $\mathrm{AB}=$ arbustivo; $*=$ Espécie exótica invasora.

Dentre as espécies, a euforbiácea Sebastiania commersoniana (branquilho) apresentou ampla hegemonia, obtendo os maiores valores para os três parâmetros fitossociológicos, com densidade de 1630 ind./ha, dominância de $30,86 \mathrm{~m}^{2} /$ ha e $100 \%$ de freqüência, o que lhe rendeu um valor de importância (VI) de 144,60, mais de seis vezes superior ao da segunda colocada (Tabela 3). Por ter tamanha influência, é que ela imprime sua coloração na paisagem, deixando-a verde-acinzentada no outono e inverno, em função de sua decidualidade foliar, verde-clara durante a primavera e verde-escura no verão.

A seguir, aparece Allophylus edulis (vacum), árvore comum da Floresta com Araucária, diferenciada das demais por ser uma das únicas desse bioma com folhas compostas trifolioladas de margem serreada. Mesmo muito abaixo de $S$. commersoniana, ela tem posição significativa em função da sua densidade (195 ind./ha) e por estar presente em 15 das 20 parcelas, atingindo VI de 21,80.

Logo após, com 18,49 de valor de importância, surge Schinus terebinthifolius (aroeira), normalmente representada por árvores de grande porte e coberta por epífitas, que se sobressaem em dominância $(3,31$ $\mathrm{m}^{2} / \mathrm{ha}$ ) e freqüência ( $55 \%$ das parcelas).

Daí para frente, o parâmetro que mais influencia na importância das espécies é a freqüência. No caso de Myrceugenia glaucescens (guamirim), mirtácea de notáveis dimensões, cujas folhas são nitidamente discolores, a densidade é o segundo parâmetro de maior contribuição. Acontece da mesma maneira com Myrrhinium atropurpureum (murtilho), árvore esguia, paucifoliada, de casca finamente fissurada e flores muito chamativas e Guettarda uruguensis (veludo), arbusto escandente de folhas opostas muito pilosas, com 
múltiplos troncos providos de antigos ramos pontiagudos, parecidos com espinhos. Contudo, para Blepharocalyx salicifolius (murta), a dominância passa a ter o papel coadjuvante, com moderada contribuição, refletindo o grande porte apresentado por esta mirtácea, que chama a atenção pelo seu tronco cilíndrico e reto e casca tipicamente fissurada.

TABELA 3: Estimativa dos parâmetros fitossociológicos das espécies arbóreo-arbustivas da floresta aluvial do rio Barigüi.

TABLE 3: Phytosociologic parameters estimate to shrub-arboreal species of the Barigui river's floodplain forest.

\begin{tabular}{|c|c|c|c|c|c|c|c|c|}
\hline \multirow[b]{2}{*}{ Espécies } & \multirow[b]{2}{*}{$\mathrm{N}$} & \multicolumn{2}{|c|}{ Densidade } & \multicolumn{2}{|c|}{ Dominância } & \multicolumn{2}{|c|}{ Freqüência } & \multirow[b]{2}{*}{ VI } \\
\hline & & $\begin{array}{c}\text { DA } \\
(\mathrm{n} / \mathrm{ha})\end{array}$ & $\begin{array}{l}\text { DR } \\
(\%)\end{array}$ & $\begin{array}{c}\text { DoA } \\
\left(\mathrm{m}^{2} / \mathrm{ha}\right)\end{array}$ & $\begin{array}{c}\text { DoR } \\
(\%)\end{array}$ & $\begin{array}{l}\text { FA } \\
(\%)\end{array}$ & $\begin{array}{l}\text { FR } \\
(\%)\end{array}$ & \\
\hline Sebastiania commersoniana & 326 & 1630 & 60,3 & 30,864 & 70,59 & 100 & 13,77 & 144,6 \\
\hline Allophylus edulis & 39 & 195 & 7,22 & 1,856 & 4,24 & 75 & 10,34 & 21,8 \\
\hline Schinus terebinthifolius & 18 & 90 & 3,33 & 3,314 & 7,58 & 55 & 7,59 & 18,49 \\
\hline Myrceugenia glaucescens & 23 & 115 & 4,25 & 1,553 & 3,55 & 55 & 7,59 & 15,39 \\
\hline Myrrhinium atropurpureum & 26 & 130 & 4,81 & 0,750 & 1,72 & 60 & 8,28 & 14,8 \\
\hline Blepharocalyx salicifolius & 9 & 45 & 1,66 & 1,364 & 3,12 & 30 & 4,14 & 8,92 \\
\hline Guettarda uruguensis & 11 & 55 & 2,03 & 0,228 & 0,52 & 35 & 4,83 & 7,38 \\
\hline Lithraea brasiliensis & 6 & 30 & 1,11 & 0,430 & 0,98 & 25 & 3,45 & 5,54 \\
\hline Machaerium paraguariense & 10 & 50 & 1,85 & 0,285 & 0,65 & 20 & 2,76 & 5,26 \\
\hline Scutia buxifolia & 5 & 25 & 0,92 & 0,106 & 0,24 & 20 & 2,76 & 3,93 \\
\hline Campomanesia xanthocarpa & 3 & 15 & 0,55 & 0,378 & 0,86 & 15 & 2,07 & 3,49 \\
\hline Luehea divaricata & 2 & 10 & 0,37 & 0,707 & 1,62 & 10 & 1,38 & 3,37 \\
\hline Picramnia parvifolia & 3 & 15 & 0,55 & 0,045 & 0,1 & 15 & 2,07 & 2,73 \\
\hline Hovenia dulcis & 3 & 15 & 0,55 & 0,235 & 0,54 & 10 & 1,38 & 2,47 \\
\hline Ligustrum vulgare & 2 & 10 & 0,37 & 0,143 & 0,33 & 10 & 1,38 & 2,08 \\
\hline Sebastiania brasiliensis & 3 & 15 & 0,55 & 0,030 & 0,07 & 10 & 1,38 & 2,00 \\
\hline Myrciaria tenella & 2 & 10 & 0,37 & 0,074 & 0,17 & 10 & 1,38 & 1,92 \\
\hline Syagrus romanzoffiana & 2 & 10 & 0,37 & 0,030 & 0,07 & 10 & 1,38 & 1,82 \\
\hline Casearia decandra & 2 & 10 & 0,37 & 0,026 & 0,06 & 10 & 1,38 & 1,81 \\
\hline Dalbergia frutescens & 2 & 10 & 0,37 & 0,023 & 0,05 & 10 & 1,38 & 1,8 \\
\hline Eugenia uniflora & 2 & 10 & 0,37 & 0,022 & 0,05 & 10 & 1,38 & 1,8 \\
\hline Myrcianthes gigantea & 1 & 5 & 0,18 & 0,050 & 0,11 & 5 & 0,69 & 0,99 \\
\hline Inga marginata & 1 & 5 & 0,18 & 0,048 & 0,11 & 5 & 0,69 & 0,99 \\
\hline Prunus sellowii & 1 & 5 & 0,18 & 0,021 & 0,05 & 5 & 0,69 & 0,92 \\
\hline Vitex megapotamica & 1 & 5 & 0,18 & 0,018 & 0,04 & 5 & 0,69 & 0,92 \\
\hline Eugenia uruguayensis & 1 & 5 & 0,18 & 0,017 & 0,04 & 5 & 0,69 & 0,91 \\
\hline Calyptranthes concinna & 1 & 5 & 0,18 & 0,013 & 0,03 & 5 & 0,69 & 0,9 \\
\hline Trichilia elegans & 1 & 5 & 0,18 & 0,009 & 0,02 & 5 & 0,69 & 0,9 \\
\hline Xylosma pseudosalzmannii & 1 & 5 & 0,18 & 0,009 & 0,02 & 5 & 0,69 & 0,9 \\
\hline Subtotais & 507 & 2535 & 93,71 & 42,648 & 97,53 & 635 & 87,59 & 278,8 \\
\hline Mortas & 30 & 150 & 5,55 & 1,032 & 2,36 & 75 & 10,34 & 18,25 \\
\hline Totais & 541 & 2705 & 100 & 43,73 & 100 & 725 & 100 & 300 \\
\hline
\end{tabular}

Em que: $\mathrm{N}=$ número de indivíduos; $\mathrm{DA}=$ densidade absoluta; $\mathrm{DR}=$ densidade relativa; $\mathrm{D}_{0} \mathrm{~A}=$ dominância absoluta; $\mathrm{D}_{0} \mathrm{R}=$ dominância relativa; $\mathrm{FA}=$ freqüência absoluta; $\mathrm{FR}=$ freqüência relativa; $\mathrm{VI}=$ valor de importância.

É interessante ressaltar que somente as sete espécies citadas perfazem $83,55 \%$ do total de indivíduos da comunidade avaliada. Ao considerar também as árvores mortas, de posição destacada (VI - 18,25), à frente até de Myrceugenia glaucescens, em função, sobretudo, da sua assiduidade nas parcelas (75\% de freqüência), chega-se a $89,09 \%$.

Nota-se, ainda, a entrada de duas espécies exóticas na comunidade: Hovenia dulcis e Ligustrum 
vulgare já ocupam posições intermediárias de importância, refletindo uma significativa mudança que vem ocorrendo no ambiente, causada pela forte pressão antrópica, sobretudo pelo rebaixamento do lençol freático resultante da "regularização" do rio Barigüi e da abertura de inúmeros drenos.

Com relação aos índices de diversidade, foram encontrados 1,595 para o índice de Shannon (H'), 0,427 para o de Simpson (C) e 0,474 para a equabilidade. Esses números indicam uma baixa diversidade para a comunidade, explicada muito mais pela segmentação do ambiente aluvial, restrito a uma pequena faixa de hidromorfia, do que propriamente pela pobreza de espécies encontradas na planície. Tanto assim, que os valores para o índice de Shannon de florestas homólogas do interior paulista, calculados com mesma base logarítmica e sob mesmo critério de inclusão (perímetro mínimo de $15 \mathrm{~cm}$ ), onde não houve esse tipo de preocupação, são sempre superiores a 2,5 (Costa et al., 1997).

\section{Distribuição horizontal e vertical dos indivíduos}

Quanto à análise da distribuição vertical, foram definidas três posições sociológicas diferenciadas (Figura 4).

O estrato superior, evidenciado principalmente entre 11 e 13 metros de altura, é formado majoritariamente $(75,8 \%)$ por $S$. commersoniana, estando representados $43,2 \%$ dos indivíduos e $48,27 \%$ das espécies, sendo exclusiva Luehea divaricata (açoita-cavalo).

O estrato intermediário esteve limitado, em sua maior parte, entre 7 e 11 metros de altura, e agrupou $44,4 \%$ dos indivíduos e $82,76 \%$ das espécies, sendo também $S$. commersoniana a mais comum (60\%).

Esse estrato marca bem a divisão de ocorrência entre algumas espécies, pois, abaixo dele, não se encontram S. terebinthifolius (aroeira), Lithraea brasiliensis (bugreiro) e Campomanesia xanthocarpa (guabiroba) e, do contrário, acima dele, não chegam Picramnia parvifolia, Casearia decandra (guaçatunga), Dalbergia frutescens (rabo-de-bugiu), Eugenia uniflora (pitanga), Calyptranthes concinna (guamirim-defacho), Trichilia elegans (catiguá) e Xylosma pseudosalzmannii (sucará).

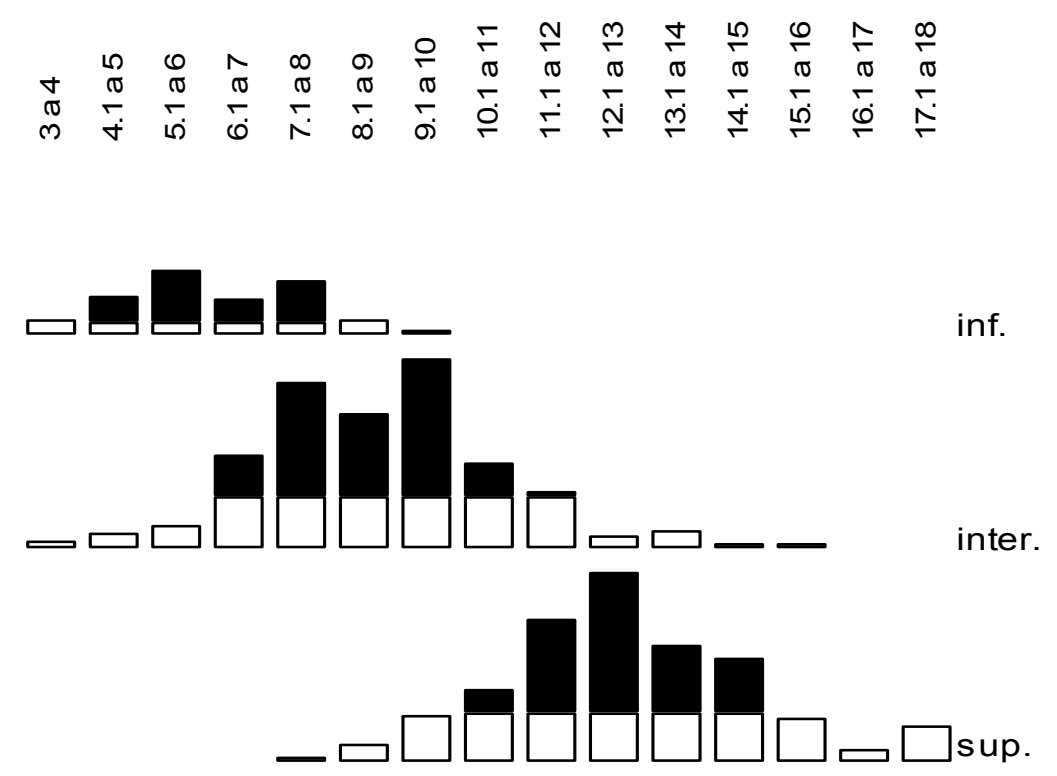

FIGURA 4: Distribuição em classes de altura $(\mathrm{m})$ e estratificação da floresta aluvial do rio Barigüi $(\mathbf{\square}=$ valores acima da média).

FIGURE 4: Classes of height and strata of the Barigüi River's floodplain forest ( $\mathbf{m}=$ above average values).

Por último, ficou definido um estrato inferior concentrado entre 5 e 6 metros que, apesar de ter apenas $12,4 \%$ dos indivíduos, quando reunido aos exemplares de diâmetros inferiores a $15 \mathrm{~cm}$, torna-se fisionômica e estruturalmente significativo. Mesmo contando com poucos representantes, concentrou $48,27 \%$ das espécies, das quais, mais uma vez, S. commersoniana é a mais destacada, com $38,10 \%$ do total. 
Destes resultados, pode-se notar que os indivíduos encontrados nesta condição possuem alturas bem mais baixas do que aqueles observados nas áreas melhor drenadas dos interflúvios, onde predominam as florestas com araucária, que podem atingir entre 25 e $38 \mathrm{~m}$ de altura (Leite e Klein, 1990; Pizatto, 1999). Talvez isso aconteça pela impossibilidade do aprofundamento das raízes, pela maior luminosidade (ambiente é mais aberto) e pela menor competição entre espécies nos ambientes hidromórficos. Observou-se, ainda, que as alturas dos estratos variam com as condições de saturação hídrica do solo, tendo médias mais altas em locais de melhor aeração e mais baixas nos mais influenciados pela água.

Analisou-se também, a distribuição por classes de área transversal "g" $\left(\mathrm{m}^{2}\right)$, uma vez que quase um terço $(31,36 \%)$ dos indivíduos vivos estudados tinham mais de um tronco e 44,83\% das espécies apresentaram no mínimo um representante com essa característica, inviabilizando a análise diamétrica diretamente.

Assim, notou-se acentuada concentração de indivíduos nas menores classes de área transversal (Figura 5), sendo de 70,22\% os seus exemplares entre 0,0018 e $0,0113 \mathrm{~m}^{2}$, equivalentes a 4,8 e $12 \mathrm{~cm}$ de diâmetro, sendo, por outro lado, de apenas $7,5 \%$ os que alcançaram áreas transversais maiores do que $0,0529 \mathrm{~m}^{2}$, que corresponderiam a $26 \mathrm{~cm}$ de diâmetro. Entre as árvores de maiores dimensões estão Blepharocalyx salicifolius, Luehea divaricata, Schinus terebinthifolius (maior área transversal entre as árvores de tronco único - 0,0998 $\mathrm{m}^{2}$, ou seja, $35,7 \mathrm{~cm}$ de diâmetro) e $S$. commersoniana, com $0,1585 \mathrm{~m}^{2}$, de um exemplar de quatro troncos, que teria um diâmetro equivalente a $44,9 \mathrm{~cm}$.

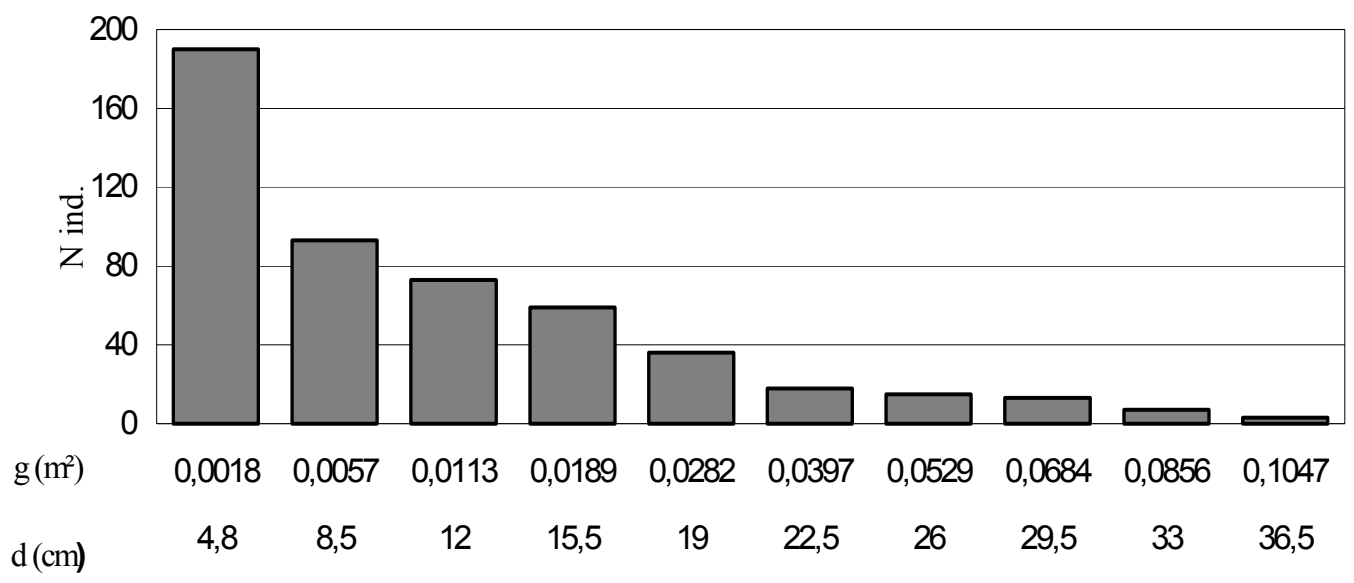

Limite inferior de classes

FIGURA 5: Distribuição dos indivíduos por área transversal e diâmetros equivalentes para a floresta aluvial do rio Barigüi.

FIGURE 5: Individual distribution by transversal area and equivalent diameters to the floodplain forest of the Barigui River.

Novamente, se comparadas às florestas com araucária dos interflúvios (Pizatto, 1999; Durigan, 1999), nota-se que essas comunidades aluviais são formadas por indivíduos de pequenos diâmetros, os quais talvez não tenham maior incremento devido à vida mais curta das principais espécies.

O perfil esquemático (Figura 6) permite melhor visualização do ambiente, pois mostra a estrutura da floresta, além da profundidade média dos horizontes do solo e do lençol freático. 


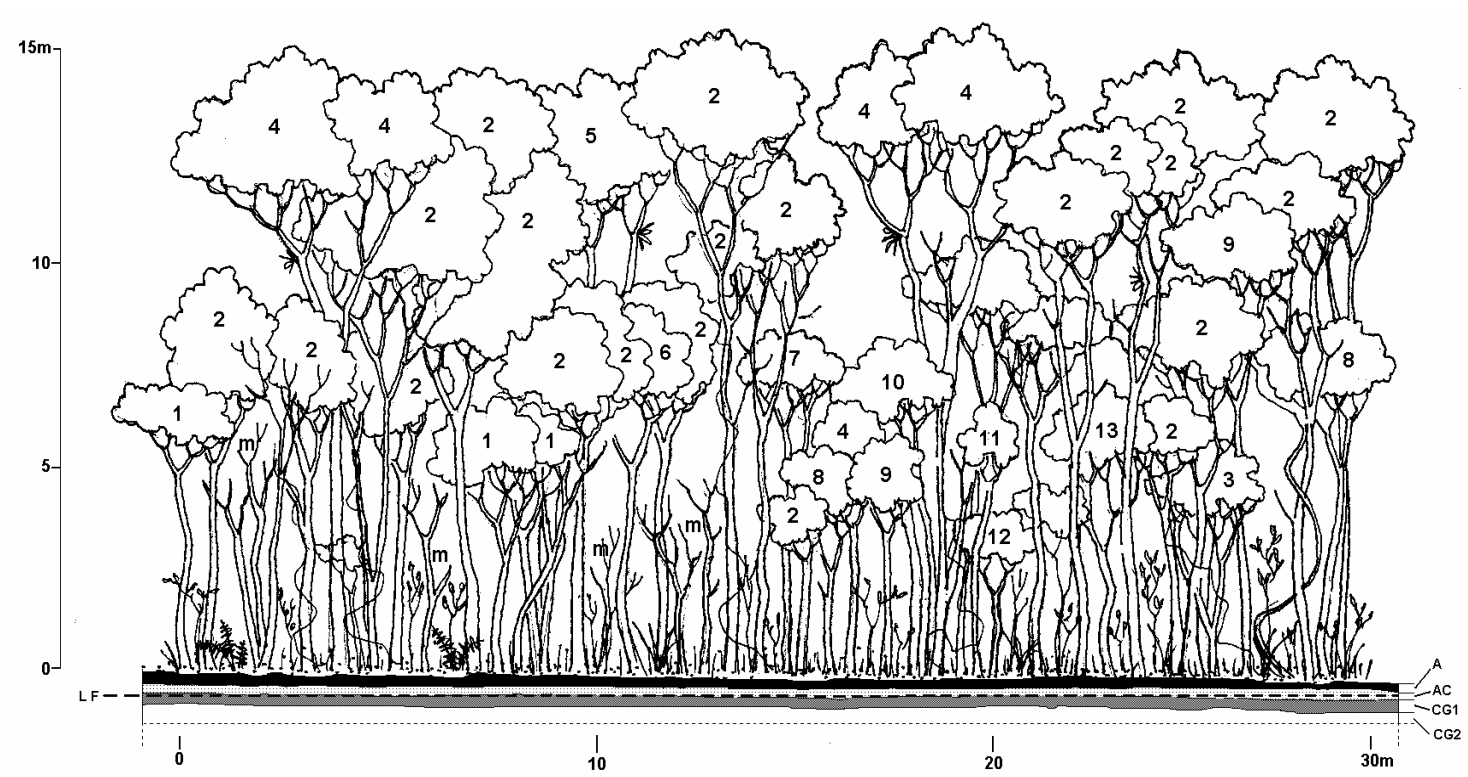

Legenda:

1- Eugenia uruguayensis

2- Sebastiania commersoniana

6- Vitex megapotamica

7- Dalbergia frutescens

8- Allophylus edulis

9- Schinus terebinthifolius

10- Machaerium paraguariense
11- Calyptranthes concinna

12- Guettarda uruguensis

13- Scutia buxifolia

m- Morta

LF-Lençol frático

5- Campomanesia xanthocarpa

$\mathrm{A}, \mathrm{AC}, \mathrm{Cg} 1, \mathrm{Cg} 2$ : horizontes dos solo

FIGURA 6: Perfil esquemático representativo da floresta aluvial do rio Barigüi e dos horizontes do solo, Araucária, PR.

FIGURE 6: Esquematic profile of the floodplain forest of the Barigui River and of the soil horizons, Araucaria, PR.

\section{Correlação entre os fatores físicos e a vegetação}

Demonstrando a heterogeneidade do ambiente estudado para os agrupamentos de parcelas pouco distanciados, localizados sobre mesma ordem de solos, foram encontradas variações estatisticamente significativas entre os parâmetros fitossociológicos utilizados na análise de variância. Vale ressaltar que os parâmetros que não apresentaram variâncias homogêneas não foram submetidos à análise de variância, uma vez que as condicionantes para a utilização da mesma não foram atendidas.

Utilizando-se as variáveis de todas as espécies, encontrou-se expressiva variação para a dominância. Pela comparação de Tukey, o conjunto 1, de maior dominância (DoA), foi separado apenas do conjunto 3 (Tabela 4).

TABELA 4: Teste de comparação de médias (Tukey) para os parâmetros fitossociológicos significativamente diferentes da floresta aluvial do rio Barigüi.

TABLE 4: Comparison of means test (Tukey) of phytosociologic parameters with significant differences for the Barigui River's floodplain forest.

\begin{tabular}{l|c|c|c|c}
\hline \multirow{2}{*}{$\begin{array}{c}\text { Conjuntos } \\
\text { de }\end{array}$} & $\begin{array}{c}\text { Dados de Todas } \\
\text { Espécies }\end{array}$ & \multicolumn{3}{|c}{$\begin{array}{c}\text { Dados do branquilho } \\
\text { Sebastiania commersoniana }\end{array}$} \\
\cline { 2 - 5 } Parcelas & DoA & DA & DoA & $\mathrm{dm}$ \\
\hline 1 (parc. 1-7) & $51,54 \mathrm{a}$ & $1542,9 \mathrm{ab}$ & $38,37 \mathrm{a}$ & $16,61 \mathrm{a}$ \\
2 (parc. 8-13) & $43,63 \mathrm{ab}$ & $2066,7 \mathrm{a}$ & $28,06 \mathrm{~b}$ & $11,80 \mathrm{~b}$ \\
3 (parc. 14-20) & $34,26 \mathrm{~b}$ & $1342,9 \mathrm{~b}$ & $25,77 \mathrm{~b}$ & $14,36 \mathrm{ab}$ \\
\hline
\end{tabular}

Em que: Médias seguidas pela mesma letra não diferem significativamente pelo teste de Tukey, a $5 \%$ de probabilidade; DoA = dominância absoluta, $\mathrm{DA}=$ densidade absoluta; $\mathrm{dm}=$ diâmetro médio. 
Ao usar somente os dados de Sebastiania commersoniana, espécie mais importante e representativa da comunidade, a análise de variância revelou diferenças significativas para densidade (DA), dominância (DoA) e diâmetro médio (dm).

A comparação de médias (Tabela 4) detectou, reforçando a tendência demonstrada para os dados de todas as espécies, que o conjunto 1 foi significativamente maior em dominância que os outros dois blocos, além de demonstrar que o diâmetro foi significativamente maior para o bloco 1 em relação ao bloco 2 . Comprovou-se, ainda, que o conjunto 2, de menor dominância e diâmetros, teve a maior densidade, expressivamente mais alta do que a do terceiro conjunto.

Esses dados são muito interessantes, pois parecem revelar que uma maior profundidade do lençol permitiria um melhor desenvolvimento diamétrico da comunidade e também qual o comportamento do branquilho no intuito de dominar este ambiente. A partir das evidências, pode-se inferir que, para uma hidromorfia acentuada, caso do conjunto 2, essa espécie alcança o maior valor de importância da comunidade graças a sua grande quantidade ou densidade de indivíduos. Quando a presença do lençol de água passa a ser em maior profundidade, o branquilho se mantém com os maiores parâmetros fitossociológicos devido ao seu maior desenvolvimento diamétrico, que compensa a redução do seu número de indivíduos.

Além disso, observou-se que a rugosidade da superfície do terreno, sobretudo no conjunto 2 de parcelas, gera pequenas bacias de inundação, as quais, além do acúmulo da serapilheira, promovem uma maior estagnação de água em superfície, em que se estabelece maior número de espécies de gramíneas e herbáceas, sendo raras as árvores. As microelevações do terreno, que na área foram da ordem de $15 \mathrm{a} 30 \mathrm{~cm}$ acima das pequenas bacias de inundação, proporcionam uma condição diferenciada de oxigenação, facilitando o estabelecimento das espécies arbóreas.

Desse modo é que as espécies tolerantes à hidromorfia, mas de adaptação mais limitada, conseguem competir com as demais. É o caso da maioria das espécies de baixos valores fitossociológicos (Tabela 3), como Lithraea brasiliensis, Luehea divaricata, Inga marginata, Prunus sellowii, Vitex megapotamica e Xylosma pseudosalzmanii, muitas delas representadas por apenas um indivíduo e todas com pequena distribuição pela paisagem.

\section{CONCLUSÕES E RECOMENDAÇÕES}

Mesmo para um ambiente segmentado da planície do rio Barigüi, abrangendo somente sua porção central, entre o dique marginal e a planície de inundação, os pontos proximamente localizados, sobre igual ordem de solo, tiveram diferenças significativas na estrutura e na composição da floresta. As variações encontradas se devem principalmente ao regime de hidromorfia e à rugosidade da superfície (diferenças de microrelevo), associados às características específicas que impõem ao solo.

Como resposta à segmentação do ambiente estudado e aos fatores limitantes locais, foram encontradas apenas 29 espécies na composição da comunidade, destacando-se o grande número de árvores mortas e de indivíduos com múltiplos troncos.

A principal espécie analisada foi Sebastiania commersoniana, que, nos locais de maior saturação hídrica, apresenta grande número de indivíduos de diâmetros pequenos e, nos sítios menos influenciados pela água, tem sua densidade reduzida, compensando esta perda com uma maior expansão diamétrica, permitindolhe a posição de espécie mais importante em ambas as condições.

Despontando como emergentes na floresta, foram evidenciadas principalmente: Blepharocalyx salicifolius, Lithraea brasiliensis, Luehea divaricata e a exótica Hovenia dulcis (uva-do-japão).

Como sugestões para o melhor entendimento do desenvolvimento da floresta nestas áreas tão complexas, pode-se citar a padronização metodológica de estudo e a adoção de conceitos geo-pedológicos na segmentação do ambiente fluvial, antecedendo a instalação das áreas amostradas.

Ainda, propõe-se que a medição do lençol freático tenha duração mínima de um ano, resultando em mais ampla caracterização de sua variação. 


\section{REFERÊNCIAS BIBLIOGRÁFICAS}

AB'SABER, A.N. O suporte geoecológico das florestas beiradeiras (ciliares). In: RODRIGUES, R.R. ; LEITÃO FILHO, H. de F. Matas ciliares: conservação e recuperação. São Paulo: Edusp, 2000. p.15-25.

ALMQUIST, E.B.; MESSINA, M.G.; JACK, S.B. Microtopographical effects on treefall gap formation in an east Texas bottomland hardwood forest. In: TENTH BIENNIAL SOUTHERN SILVICULTURAL RESEARCH CONFERENCE, 1999, Shreveport. Proceedings... Schreveport : USDA, Forest Service, 1999. p.166-170. (General Technical Report)

BUFREN, A. M. Caracterização fitossociológica de um remanescente de floresta ripária do rio Pequeno, São José dos Pinhais - Pr. 1997. 87p. Dissertação (Mestrado em Botânica) - Setor de Ciências Biológicas, Universidade Federal do Paraná, Curitiba, 1997.

CHRISTOFOLETTI, A. Geomorfologia fluvial : o canal fluvial. São Paulo: Edgard Blücher, 1981.

COSTA, F.R.C.; SCHLITTLER, F.H.M.; CESAR, O.; MONTEIRO, R. Aspectos florísticos e fitossociológicos de um remanescente de mata de brejo no Município de Brotas, SP. Arquivos de Biologia e Tecnologia, Curitiba, v. 40, n. 2, p. 263-270, 1997.

DANNI-OLIVEIRA, I.M. A distribuição e a variabilidade das chuvas em Curitiba/PR. In: SIMPÓSIO BRASILEIRO DE GEOGRAFIA FíSICA APLICADA, 7., 1997, Curitiba. Anais... São Paulo: Tec Art, 1997. v.1.

DAUBENMIRE, R. Plant communities: a textbook of plant synecology. New York: Harper e Row, 1968.

DNOS - Departamento Nacional de Obras e Saneamento. Rio Barigüi: canalização e regularização. Curitiba, 1979.

DURIGAN, M.E. Florística, dinâmica e análise protéica de uma Floresta Ombrófila Mista em São João do Triunfo - PR. 1999. Dissertação (Mestrado em Ciências Florestais) - Setor de Ciências Agrárias, Universidade Federal do Paraná, Curitiba, 1999.

EMBRAPA - CNPS. Manual de métodos de análise de solo. 2. ed. Brasília: Serviço de Produção da Informação; Rio de Janeiro: CNPS, 1979. 212 p.

EMBRAPA - CNPS. Sistema brasileiro de classificação de solos. Brasília: Serviço de Produção da Informação; Rio de Janeiro: CNPS, 1999. 412p.

GALVÃO, F., KUNIYOSHI, Y. S. RODERJAN, C. V. Levantamento fitossociológico das principais associações arbóreas da Floresta Nacional de Irati - PR. Revista Floresta, Curitiba, v. 19, n. 1-2, p. 30-49, 1989.

GALVÃO, F. Métodos de levantamento fitossociológico. In: Curitiba. IPARDES, CTD, 1994. 20p.

A vegetação natural do Estado do Paraná.

GURNELL, A. The hydrological e geomorphological significance of forested floodplains. Global Ecology and Biogeography Letters. Oxford, v.6, n. 3-4, p. 219-229, 1997.

IBGE. Manual técnico da vegetação brasileira. Rio de Janeiro: Departamento de Recursos Naturais e Estudos Ambientais, 1992. 92p. (Manuais Técnicos em Geociências, n.1).

IVANAUSKAS, N.M.; RODRIGUES, R.R.; NAVE, A.G. Aspectos ecológicos de um trecho da floresta de brejo em Itatinga, SP: florística, fitossociologia e seletividade de espécies. Revista Brasileira de Botânica, São Paulo, v.20, n.2, p.139-153, 1997.

LEITE, P.F.; KLEIN, R.M. Vegetação. In: IBGE. Geografia do Brasil : Região Sul. Rio de Janeiro: Diretoria de Geociências, 1990. p. 113-187.

MAGURRAN, A. E. Diversidad ecológica e su medición. Barcelona: Vedrá, 1989.

MUELLER-DOMBOIS, D.; ELLENBERG, H. Aims and methods of vegetation ecology. New York: John Wiley e Sons, 1974.

OLIVEIRA, J. B. de; JACOMINE, P.K.T.; CAMARGO, M.N. Classes gerais de solos do Brasil: guia auxiliar para seu reconhecimento. Jaboticabal: FUNEP, 1992. 201 p.

OLIVEIRA, E. A. Caracterização florística, fitossociológica e pedológica de um trecho da floresta ripária dos Campos Gerais do Paraná. 2001. 106p. Dissertação (Mestrado em Engenharia Florestal) - Setor de Ciências Agrárias, Universidade Federal do Paraná, Curitiba, 2001.

PIZATTO, W. Avaliação biométrica da estrutura e da dinâmica de uma Floresta Ombrófila Mista em São João do Triunfo - PR: 1995-1998. 1999. 172 f. Dissertação (Mestrado em Ciências Florestais) - Setor de Ciências Agrárias, 
Universidade Federal do Paraná, Curitiba, 1999.

RAUEN, M.J.; FASOLO, P.J.; POTTER, R.O.; CARDOSO, A.; CARVALHO, A.P.; HOCHMULlER, D.P.; CURCIO, G.R.; RACHWAL, M.F.G. Levantamento semidetalhado dos solos de várzea da bacia do rio Iguaçu. In: HENKLAIN, J.C. (Coord.). Potencial de uso agrícola das áreas de várzea do estado do Paraná: bacias hidrográficas dos rios das Cinzas e Laranjinha, Iapó, Iguaçu, Piquiri, Pirapó, Tibagi e litoral. Londrina: IAPAR, 1990. v.2.

RESCK, D.V.S. e SILVA, J.E. Importância das matas de galeria no ciclo hidrológico de uma bacia hidrográfica. In: Cerrado: matas de galeria. Planaltina: EMBRAPA - CPAC, 1998. p.29-46.

SHEPHERD, G.J. Fitopac 1: versão preliminar - software computacional e manual do usuário. Campinas: Depto. de Botânica da UNICAMP, 1988. 8 p.

SOUZA, M. K. F. Florística e fitossociologia do estrato arbóreo-arbustivo de diferentes compartimentos em ambiente fluvial no município de Jaguariaíva - PR. 2001. 108p. Dissertação (Mestrado em Botânica) - Setor de Ciências Biológicas, Universidade Federal do Paraná, Curitiba, 2001.

SUGUIO, K.; BIGARELLA, J.J. Ambientes fluviais. 2.ed. Florianópolis: UFSC, UFPR, 1990.

TONIATO, M.T.Z; LEITÃO FILHO, H.F.; RODRIGUES, R.R. Fitossociologia de um remanescente de floresta higrófila (mata de brejo) em Campinas, SP. Revista Brasileira de Botânica, São Paulo, v. 21, n.2, 1998.

VIVIAN-SMITH, G. Microtopographic heterogeneity and floristic diversity in experimental wetland communities. Journal of Ecology, v. 85, p.71-82, 1997. 